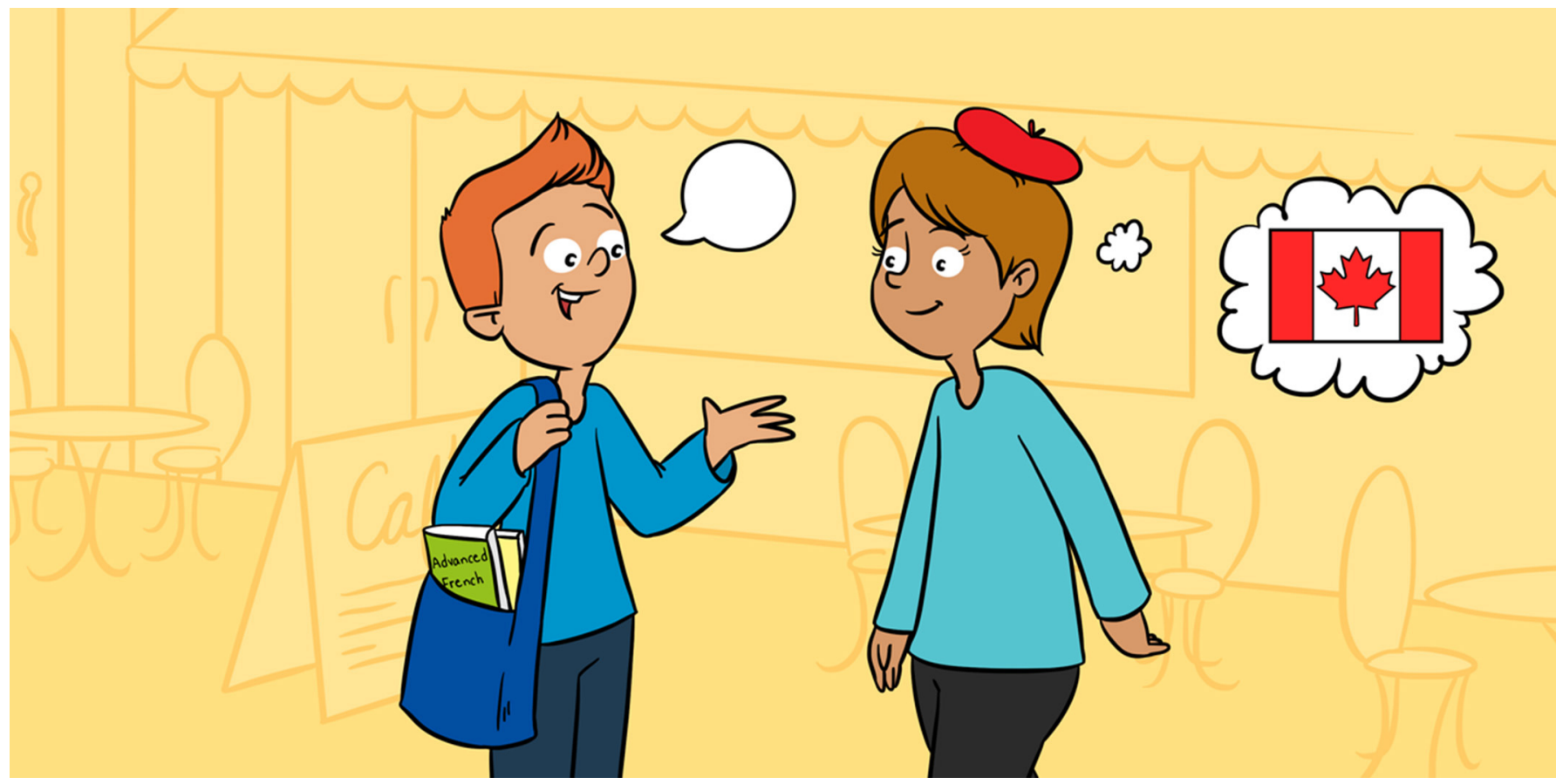

\title{
SPEAKING AND HEARING WITH AN ACCENT
}

\section{John A. Archibald *}

Department of Linguistics, University of Victoria, Victoria, BC, Canada

\section{YOUNG REVIEWER:}

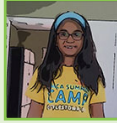

NEHA

AGE: 9

\section{ACCENT}

The properties of speech, other than vocabulary or sentence structure, that characterize the difference between a native speaker and a non-native speaker.
When we speak a second language, we tend to do so with an accent. An accent is a change of the sounds of the second language, often the result of the influence of the first language. For example, an English speaker might produce French with English " $r$ " sounds. Accents result from more than just poor muscular coordination. Second-language speakers are drawing on the unconscious rules that they already know about their first language. This body of knowledge influences not only how people speak a second language but also how they hear it. If a Japanese speaker is not accurately producing a distinction between an " $l$ " and " $r$ " sound, it is likely that the same individual will have difficulty accurately hearing the difference between the two sounds. Ultimately, bilingualism is a natural state for the human brain, even when we are speaking or listening with an accent.

\section{INTRODUCTION}

You have probably heard someone who speaks your native language with an accent. If you hear a non-native speaker say the English sentence, "I have a dog," the word "have" might sound like "av" if said 


\section{GRAMMAR}

The system of knowledge that governs your comprehension, production, and intuitions about the languages you know.

\section{SECOND}

LANGUAGE

Any additional language learned after the acquisition of your native language. by a French speaker (because French does not have an "h" sound), or "haf" if said by a German speaker (because German does not have "v" at the end of words). But you could probably understand the sentence even if you heard "I av a dog," or "I haf a dog." Why do we speak with accents when we speak another language?

There are over 6,000 languages in the world and most people on the planet know more than one of them. What do you know when you know a language? You have something in your mind known as a grammar. For linguists (scientists who study languages), a grammar is not some dusty book that might tell you not to end a sentence with a preposition. A grammar is the set of unconscious rules that tells you that, "Millions of unicorns suddenly appeared on the space station" is a possible sentence in English, while "He watches the house red" is not. Notice that you have not heard either of these sentences before, so it is not your past experience that is telling you that one is a proper sentence (although complex and imaginary) and one is not a proper sentence (although simple and real). You know because you have an internal, mental grammar.

\section{OUR BRAINS ARE MADE FOR GRAMMAR AND LANGUAGES}

Acquiring a grammar seems to be something that humans are uniquely qualified for; they are built to do it. When we think about babies learning their native languages, it is really more like growth than learning. Things that are learned tend to be learned to different levels by different people. For example, we can learn to play chess, but there are great chess players and there are horrible chess players. But that is not true of language. Everyone knows all the rules of their language, perfectly. Kind of like growing arms-everyone does it, perfectly. Just by being born into a particular environment, a child will grow that language. Put a baby in a Japanese environment, she will grow Japanese. Children are not taught how to walk, and they are not taught how to speak. Language is part of biology. But what about second languages? Second languages are any languages learned after learning your native language. Are humans built for learning second languages? In much of the world, it is certainly common to grow up speaking more than one language. Children in these situations essentially have two native languages. So, learning a second language is not something that only certain special people can do. Every child can do it.

\section{SPEAKING A SECOND LANGUAGE WITH AN ACCENT}

But what if you started learning a second language when you were older, say, 12 , or 20 , or 40 ? These people will probably have accents when they speak in the second language [1]. When native English 
speakers speak French, for example, native French listeners can tell that the speakers are non-native French speakers because of their pronunciation of French words-they have an English accent. The term "accent" usually just refers to the sounds of the language. Non-native speakers may make mistakes with the sentence structure too (like past tense, or feminine gender), but those kinds of mistakes are not part of accent.

We can describe what makes up an accent by looking at consonants and vowels. When linguists talk about sounds, they put them in square brackets like this: [k]. That indicates that we are talking about the sound [k] not the letter " $k$." You will notice that the letter " $c$ " is pronounced very differently in its occurrences in the word "electricity." The first is a [k], the second a [s]. The same is true of vowels. The letter "o" is pronounced very differently in the words "go" and "women." When we write down the pronunciation of a word, we use a phonetic alphabet. So, I could use the phonetic alphabet to show my pronunciation of words like "top" [tap] or "go" [go].

You might think that perhaps an accent is the result of difficulties with muscular control of the mouth or tongue. After all, the only thing that separates making the [s] sound at the beginning of "see" from making the [ $\left.\int\right]$ sound at the beginning of "she" is a difference of a few millimeters in where you put the tongue on the roof of your mouth. Try it and see! Similarly, a few milliseconds of time are all that separates the length of the [i] vowel in "bead" from the [I] vowel in "bid." If we mispronounce second-language sounds by just a few millimeters or milliseconds, we will have a recognizable accent.

\section{ACCENTS AFFECT THE SPEAKING AND HEARING OF A SECOND LANGUAGE}

So, could it be true that when we speak a second language with an accent, it is just because our muscles are accustomed to moving like they do in our native language, so what comes out of our mouths is something like French with English sounds? The short answer is "no," but the longer answer is more complicated [2].

We begin with the observation that accents affect the way we hear a second language, as well as the way we speak it. One of the things you need to learn when learning a second language is which sounds can change the meaning of a word. This is called contrast. For example, in English, if we change an [l] sound to an [r] sound, it will change the meaning of the word (as in read/lead). When we listen to a language that makes contrasts that our native language does not, the contrasts can be difficult to hear at first. Japanese does not have an [r] vs. [l] contrast, and Japanese people have a hard time hearing the difference between these sounds when listening to English. Also, English lacks a contrast that Japanese has: long vs. short consonants. For example, 


\section{DISCRIMINATION}

The ability to tell that two items (in our case, words or sounds) are different.

\section{PERCEPTUAL}

\section{ACCURACY}

The ability to recognize two different sounds as different, and two identical sounds as identical.

\section{ILLUSORY VOWEL}

A vowel perceived by a listener which has not actually been produced by the speaker.

\section{CONSONANT CLUSTER}

A sequence of two or more consonants. For example, the "pl" in "play." the Japanese word meaning to come [kite] (with a short [t]) means something different from the word meaning postage stamp [kitte] (with a long [tt]).

How do we know that the listeners cannot hear the difference? The simplest way is to give listeners a discrimination test. Discrimination is the ability to tell two things apart or, in this case, to tell that two words or sounds are different. The listeners hear two words (like "rake" and "lake") and they must determine whether the words are the same or different. Someone who can reliably perceive the difference would score very highly on the test (perfect would be 100\%), while someone who cannot hear the difference would be guessing and would score around $50 \%$. We can use these test scores to measure someone's perception accuracy, which is the ability to hear sound distinctions. A person with low perception accuracy will probably also speak with an accent.

\section{ANOTHER CONTRIBUTOR TO ACCENT: ADDING VOWELS THAT DO NOT EXIST}

There is another interesting phenomenon related to low perception accuracy in a second language: illusory vowels. Illusory vowels are almost like someone hearing imaginary vowels, hearing vowels that are not really there. To illustrate this, let us look at another way languages can differ: consonant clusters. English (and many other languages, including German) allows words to begin with more than one consonant (a cluster), as seen in words like "stop," "snow," and "slow." Languages like Brazilian Portuguese (and many other languages, including Japanese) do not allow [st] or [sl] or [sn] clusters. When speakers of Brazilian Portuguese pronounce a word that begins with one of these s-clusters, they make it pronounceable by adding an illusory vowel before the [s]. So, a word like "stop" would be pronounced [i]stop-[i] is the illusory vowel that Brazilian Portuguese speakers use; other languages use other vowels.

This leads us to the interesting question of what Brazilian Portuguese speakers hear when they listen to the word "stop" spoken by an English speaker. Let us look at the results of a discrimination test. When listeners are presented with the word pair "istop/istop," they correctly respond SAME, which tells us that they can hear vowels at the beginning of a word. When they hear "istop/stop" they incorrectly respond SAME, which tells us that they hear an [i] at the beginning of "stop." It is their grammar of Brazilian Portuguese that leads them to expect a vowel there, so they actually hear it there!

There is also evidence from measuring brain activity that supports these conclusions. Linguists have ways of measuring the electrical activity generated in the brain by placing special caps with electrodes on a person's head, as shown in Figure 1. The electrodes can measure 
Figure 1

A cap with electrodes, used for measuring the electrical activity happening in the brain

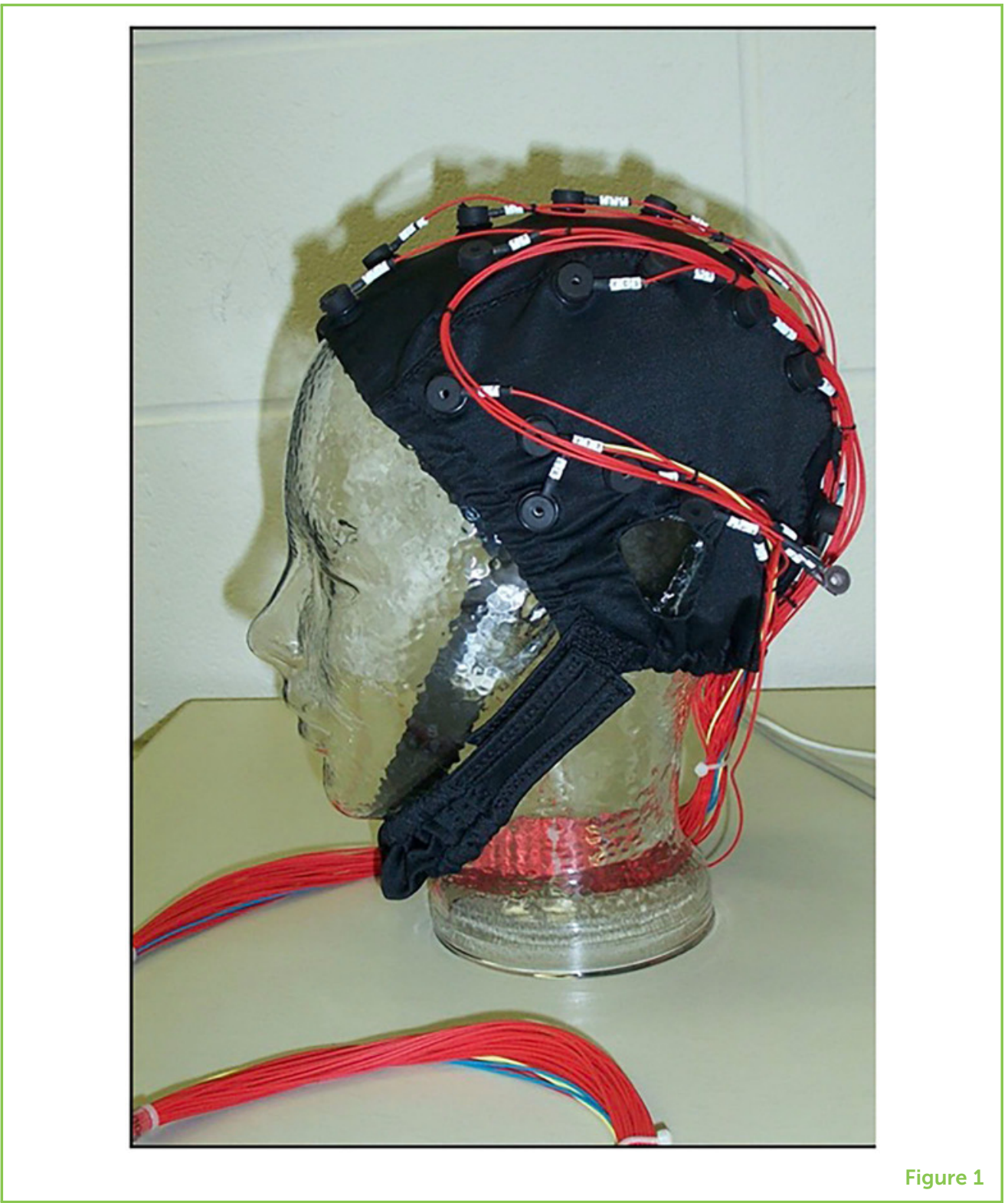

the microvolts of electricity that the brain generates when listening to words. When monitoring these signals, we can see that the brain has a particular reaction when it is surprised by something (Figure 2). Imagine that we play an English listener the words "slow," "snow," "slow." About $100 \mathrm{~ms}$ (a millisecond is 1/1,000 of a second) after the beginning of the second word, we would see a surprise reaction in the brain's activity. The surprise signal means the listener perceives the difference between the words. Now imagine that we play a Brazilian Portuguese listener the words "stop, istop, stop." Interestingly, there would be no surprise reaction in the brain at all. All three words sound the same to this listener's ears. This does not have anything to do with understanding the meaning of words like "snow" or "slow" (so it is not about comprehension), but rather it is an unconscious difference in the way the brain hears the words. 
Figure 2

The brain's surprise reaction in a word discrimination task. The squiggly lines show the electrical activity in the brain over time. Each line represents words starting with a different sound (in this case, the "r" sounds of English, French, and Spanish). The darkest line (English " $r$ ") shows a surprise reaction (the large dip in the dark line) indicating that the English " $r$ " stands out for the listener but the difference between the French and Spanish " $r$ " sounds is not perceived.

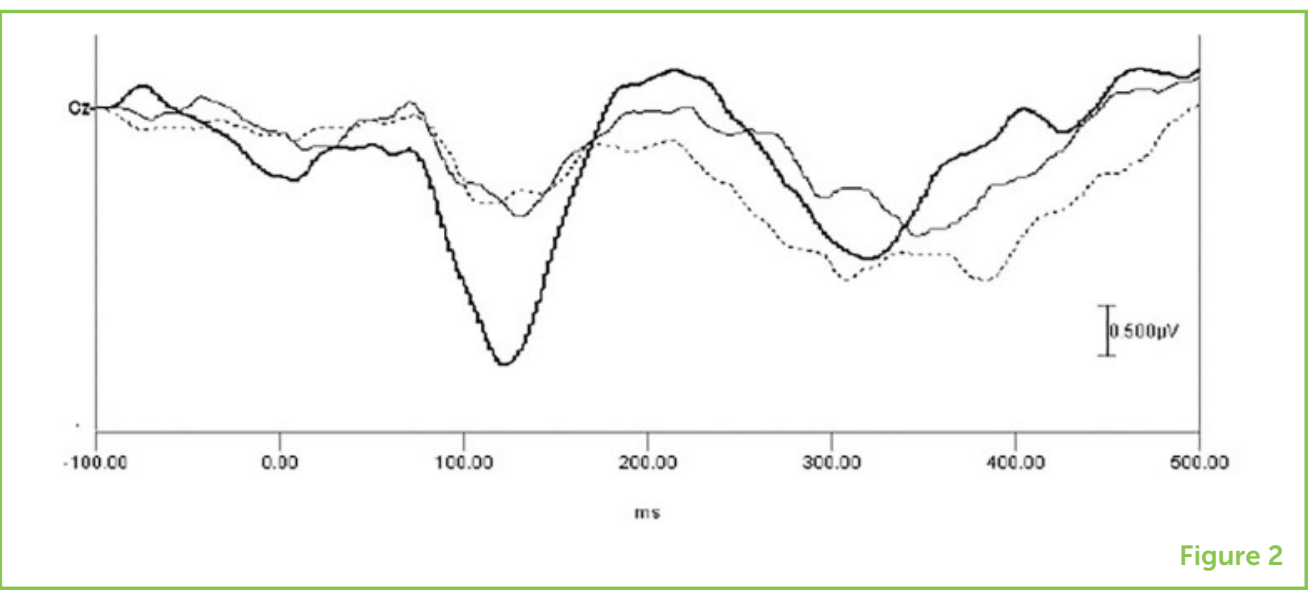

\section{CONCLUSION}

What all of this tells us is that speaking with an accent is not just a muscular issue. Accents are the result of grammars, and they affect the way we hear a language, not just the way we speak that language. But, while it is true that most people who start learning a second language as teenagers or adults will probably have an accent, this does not necessarily mean that they are hard to understand. Studies have shown that highly accented speech can be perfectly intelligible. So, when you are listening to someone talk with an accent, remember that they are listening with an accent too!

\section{REFERENCES}

1. Colantoni, L., Steele, J., and Escudero, P. 2015. Second Language Speech. Cambridge:Cambridge University Press.

2. Hansen Edwards, J., and Zampini, M. (Eds.). 2008. Phonology and Second Language Acquisition. Amsterdam:John Benjamins.

SUBMITTED: 09 July 2020; ACCEPTED: 19 February 2021;

PUBLISHED ONLINE: 22 March 2021.

EDITED BY: Lauren Jantzie, Johns Hopkins University, United States

CITATION: Archibald JA (2021) Speaking and Hearing With an Accent. Front. Young Minds 9:581824. doi: 10.3389/frym.2021.581824

CONFLICT OF INTEREST: The author declares that the research was conducted in the absence of any commercial or financial relationships that could be construed as a potential conflict of interest.

COPYRIGHT @ 2021 Archibald. This is an open-access article distributed under the terms of the Creative Commons Attribution License (CC BY). The use, distribution or reproduction in other forums is permitted, provided the original author(s) and the copyright owner(s) are credited and that the original publication in this journal 


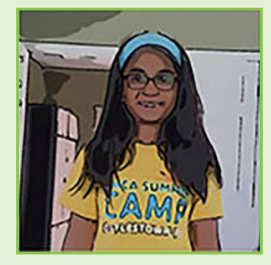

is cited, in accordance with accepted academic practice. No use, distribution or reproduction is permitted which does not comply with these terms.

\section{YOUNG REVIEWER}

\section{NEHA, AGE: 9}

Neha loves sports, riding horses, swimming, and reading books. She is very interested in learning everything she can about horses and dogs, and loves learning about the human body. She is excited about reading articles and learning more things about science.

\section{AUTHOR}

\section{JOHN A. ARCHIBALD}

Dr. John Archibald teaches linguistics on the beautiful west coast of Canada. He has done research which shows that what children and adults who are learning the sounds of new languages know is actually just as complex as the knowledge they have about sentences. By looking at languages as diverse as Mayan, Polish, Finnish, Arabic, and Japanese, he has shown that studying both second language perception and production is critical to understanding what is in our minds and brains. *johnarch@uvic.ca 